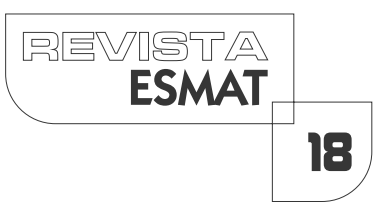

\title{
IDEOLOGIA DA NORMA JURÍDICA
}

IDEOLOGY OF LEGAL NORM

Ricardo Castilho

Pós-Doutor em Direito, pela Universidade Federal de Santa Catarina (UFSC). Doutor em Direito, pela Pontifícia Universidade Católica, de São Paulo (PUCSP). Professor titular do programa stricto sensu da Faculdade Autônoma de Direito, de São Paulo (FADISP). Diretor geral da Escola Paulista de Direito (EPD). Autor de vários livros editados pela Saraiva.

Graziele Lopes Ribeiro

Doutoranda em Direito, pela Faculdade Autônoma de São Paulo. Mestre em Direito Internacional Econômico, pela Universidade Católica de Brasília. Graduada em Direito, pela Universidade de Marília e com estudos de pós-graduação em Direito. Advogada e docente de graduação e pós-graduação em Direito.

\section{RESUMO}

presente trabalho traz como pano de fundo a manifestação do fenômeno ideológico. $\bigcirc$ ponto de partida para a análise fixa-se na Escola Histórica do Direito com suas bases historicistas e nas constatações que Marx faz ao perceber a incongruência entre a defesa do positivismo histórico proclamado por Savigny e o concretizado, sob a influência de uma ideologia classista, quando da sua atuação como legislador da Prússia. Descrevem-se as características do processo ideológico, sua identificação e suas formas de atuação. Analisa-se o pensamento marxista que constata a sobreposição de interesses de classes dominantes que moldam o pensamento coletivo numa projeção de dominação. Inserem-se nesse contexto a apreciação da influência ideológica no direito e o embate criado pela manipulação jurídica direcionada pelo fator econômico. Observa-se a manifestação ideológica no campo jurídico, desde a conceituação da ciência com seus princípios norteadores até a completa alienação de escopo, origem e fim do direito.

PALAVRAS-CHAVE: Ideologia. Ideologia Jurídica. Influência Econômica.

\section{ABSTRACT}

The present work presents as a backdrop the manifestation of the ideological phenomenon. The starting point for the analysis is fixed in the historical School of Law with its historicists bases and in the findings that Marx makes when perceiving the incongruence between the defense of the historical positivism proclaimed by Savigny and the concreted, under the influence of a Classist ideology, when acting as a Prussian legislator. The characteristics of the ideological process, its identification and its forms of action are described. It analyzes the Marxist thought that verifies the 
overlap of interests of dominant classes that shape collective thinking in a projection of domination. In this context, the assessment of the ideological influence in the law and the clash created by the legal manipulation directed by the economic factor is inserted. It is observed the ideological manifestation in the legal field, from the conceptuation of science with its guiding principles to the complete alienation of scope, origin and end of law.

KEYWORDS: Ideology, Legal ideology. Economic influence.

\section{INTRODUÇÃO}

O presente trabalho propõe a análise da influência da ideologia no direito numa perspectiva econômica. O ponto de início para a investigação fixa-se na Escola Histórica do Direito, por meio da análise da figura de seu maior expoente: Friedrich Carl Von Savigny. Ao analisar os marcos fundamentais defendidos pela escola alemã e as atitudes práticas de Savigny, Marx desperta para a existência de um sistema de ideias capaz de distorcer a realidade e impedir que o real seja apreendido, o que impossibilita que as relações sociais, políticas e econômicas sejam analisadas livres de interferências ou condicionamentos.

Avaliando essa distorção entre ideias e realidade, Marx retoma a definição adotada por Napoleão, ao designar os opositores de seu regime como metafísicos e ideólogos. Nessa perspectiva, o termo ideologia dissemina-se como sinônimo de processo que impede ou dificulta a percepção da realidade, atuando como cortina ou véu que não permite a análise do real de forma independente. As análises marxistas vão além e constatam um direcionamento do pensamento coletivo dirigido pelas classes detentoras do poder.

Por meio da exploração da incidência ideológica no campo jurídico - a partir da constatação de que o direito é composto por regras coercitivas, editadas e mantidas por um sistema político, a sua desvinculação ideológica parece impossível-, foram coletados múltiplos argumentos que se complementam e simultaneamente se contrapõem num exercício de pesquisa bibliográfica e dialética de pontos de vista adversos.

O trabalho se encerra no exame da sociedade capitalista a partir da ideologia de mercado, espaço no qual somente a utilidade econômica tem peso na balança do valor, e as necessidades humanas (valor-fonte do direito) permanecem, quando não banidas, relegadas a planos juridicamente inferiores.

\section{SAVIGNY E A ESCOLA HISTÓRICA DO DIREITO}

Friedrich Carl Von Savigny é reconhecido como o maior expoente da Escola Histórica do Direito, também chamada de Escola Histórica dos Juristas Alemães (CUSTÓDIO, 20I3). O jurista baseou seus trabalhos em Gustav Hugo, da Univer- 
sidade de Göttingen, diferenciando-se deste quanto ao distanciamento da Escola do Direito Natural, que influenciava, ainda que levemente, o professor Gustav Hugo (ASHTON, 20I3).

Gustav Hugo estabeleceu as bases críticas ao direito, definindo-o como fato histórico da tradição, da cultura específica de um povo. Propôs a criação de um direito positivo como fenômenohistórico, em contrariedade a um produto da razão dogmática.

Em Savigny, o trabalho dos juristas não consistia em raciocinar sobre a construção e a elaboração de uma ordem jurídica adequada aos homens, mas especificamente colher o objeto jurídico já produzido pelo espírito do povo e, em seguida, ordenar e sistematizar essa matéria jurídica coletada (ASHTON, 20I3). O jurista entendia o direito como um produto histórico que nasce da consciência de cada povo, baseado nos seus costumes, e não mera vontade do legislador (GONZAGA, 20 l7).

Fundado nesses argumentos, Savigny publicou um texto sob o título: "Da necessidade de um código civil para a Alemanha" (ENDERLE, 2005). No documento, foram apresentadas duras críticas a seu colega de universidade, Anton Justus Thibaut, que havia defendido, inspirado no Código Civil de Napoleão, a unificação da legislação alemã.

Thibaut defendia uma visão racional do jusnaturalismo e acreditava na necessidade de fundir todas as leis em vigor, nos diversos estados alemães, em um único código. Inspirado em Wolf, acastelava a ideia de que um conjunto racional de direitos naturais deve permitir a construção sistemática de um grupo de elementos de direito positivo em código único, ordenado de maneira lógico-sistemática (BILLIER; MARYIOLI, 2005).

As críticas de Savigny foram materializadas no texto "Da vocação da nossa época para a legislação e a jurisprudência” (JOUANJAN, 2003). Nesse estudo, defendeu que, naquele momento, o direito alemão estava em declínio, portanto,positivá-lo seria transmitir à posteridade um direito decadente. Todavia, o autor não definiu um momento que considerasse adequado para a codificação, uma vez que nenhuma das três fases por ele mencionadas - formação, maturidade e decadência do direito - reunia as qualidades ideais para a elaboração de um código (ENDERLE, 2005).

No tratado acima citado, o alemão instituiu que o "direito investe o Estado, não procede dele, pois é uma parte da existência orgânica da comunidade" (CUSTÓDIO, 2013, p. 14). Talvez por essa razão, alguns reconheçam Savigny como um anarquista ou, ao menos, um compartilhador de direitos da sociedade contra o Estado (MICHEL, 1986).

desprezo de Savigny pelas codificações era tão grande que, ao assumir a primeira cadeira de Direito Civil na Prússia - de 1810 a 1819 -, ele ensinou direito romano, a despeito do Código Prussiano vigente. A Escola Histórica simplesmente ignorava o Códex como fonte de direito (WIEACKER, 1967).

Nesse ponto, cabe uma ressalva peculiar: Savigny, ao contrário do que possa transparecer, era um positivista, mas renegava o positivismo dogmático na defesa 
de um positivismo histórico. Alguns afirmam que esse posicionamento político de Savigny se expressa muito mais como oposição a uma codificação fundada nas ideias libertárias francesas do que como valorização do indeterminado espírito do povo. Críticas à escola alemã descrevem uma atitude menos espiritual quando mais se fala do espírito. Em Hengel, o sinal mais peculiar da escola seria a aversão à lei (SOBREIRA FILHO, 20I I).

Com Savigny, o direito deveria se desenvolver filosófica - por meio de conceitos organizados, elaborados de forma sistemática - e historicamente, em estreita ligação com as raízeshistóricas da sua criação (COSTA, 2008, p. 58).

A exigenciametodológica imposta por Savigny na fundação de uma verdadeira ciência do direito consistia em considerar o objeto - direito -, de uma só vez, como história e como sistema. Trata-se de pensar numa unidade orgânica de considerações históricas e considerações sistemáticas (JOUANJAN, 2003).

Em Savigny, interpretar consiste na reconstrução do pensamento emanado da lei (JOUANJAN, 2003). Verifica-se a inserção do elemento histórico na hermenêutica como meio de assegurar a interpretação da norma, observando as condições históricas quando de sua elaboração, uma vez que a lei é fruto de determinadas ocorrências históricas, e não para asseverar que a lei seja interpretada, amoldando-se aos valores históricos do momento da aplicação. De tal modo, reflete um emprego conservador do elemento histórico, pois vincula o sentido da lei à ocasião de sua elaboração, não permite a implantação de novos institutos e contribui para a manutenção do direito germânico tradicional, impedindo codificações estatais e contrapondo-se à concepção modernizadora do positivismo (COSTA, 2008).

O escopo da escola alemã era garantir a hegemonia do passado (COSTA, 2008). O processo jurídico da Escola Histórica, em ataque à razão legisladora, direcionava-se exclusivamente para a identificação, nas raízes do positivismo, "de uma permanência, uma continuidade histórica a ser interpretada, consagrada, jamais inovada, desviada" (ENDERLE, 2005, p. II3).

Importante ressaltar que a Escola Histórica do Direito se associava às ideias das teorias burguesas e às opiniões de Adam Smith; pregava a autonomia da sociedade ante o regramento do Estado, considerando tais intervenções deletérias e prejudiciais; e afirmava que a sociedade era um organismo biológico vinculado a um espírito autônomo e recôndito - que representava genuinamente a sociedade burguesa (ASHTON, 20I3).

É ali, na sociedade, e não no Estado que é formulado o Novo Direito baseado na Ciência Burguesa, representada pela Escola Histórica do Direito e pelo seu Direito das Pandectas. Portanto, o autêntico Direito da sociedade burguesa não deve ser um produto de leis estatais, como ocorre no Direito Natural.(ASHTON, 20 I3, p. 224) 


\section{AS ANÁLISES DO JOVEM KARL MARX}

Durante um período, Savigny se afastou da academia para ocupar o cargo de ministro para a Reforma da Legislação Prussiana. Na ocasião, trabalhou na revisão da legislação e participou da formulação do General Bills Exchenge Code e do General German Commercial Code (ASHTON, 20I3).

A nomeação de Savigny como ministro incitou Karl Marx, seu aluno,' a escrever, em agosto de 1842, o "Manifesto Filosófico da Escola Histórica do Direito". Neste artigo, o jovem Marx faz duras críticas a Gustav Hugo, reconhecido por ele como precursor da Escola Histórica do Direito (ENDERLE, 2005), e classifica o trabalho de Gustav Hugo de antigo testamento da Escola Histórica. Ataca-o, ao dizer que, apesar de se autointitular discípulo de Kant, Gustav Hugo falseia seu mestre, critica a sua doutrina e questiona se os seguidores de Gustav Hugo teriam vocação para serem legisladores daquele tempo (MARX, 2006). Ataca também os representantes modernos da escola alemã, ao afirmar que promoviam, na filosofia de Gustav Hugo, uma maquiagem de conceitos fundamentais para torná-la mais atraente, sem, contudo, perder o núcleo, decifrado por um olhar atento do direito, do poder arbitrário em todas as versões da Escola Histórica ( ENDERLE, 2005.).

Inicialmente, a crítica ao "Manifesto Filosófico da Escola Histórica do Direito" era para ter sido publicada na revista de um hegeliano, Arnold Ruge. Entretanto, a publicação não foi aceita, e as ideias se juntaram a outras numa série de escritos publicados mais tarde pela Gazeta Renana, momento em que Marx discutiu a lei sobre o furto de lenhas (SOBREIRA FILHO, 20 I I).

Como ministro para a Reforma da Legislação Prussiana, coube a Savigny produzir uma lei que regularia a colheita de pedaços de madeiras caídas, nas florestas situadas à beira do rio Reno. O projeto de lei elaborado pelo precursor da Escola Histórica do Direito, que se notabilizou pela defesa do direito costumeiro contra "a vocação do nosso tempo para a legislação", previa como roubo a catação de lenha e estabelecia pena de multa ou trabalho forçado a quem praticasse o ato, que devia ser paga ao dono da floresta - propriedade (GUERRA FILHO, 1995).

O fato desprezado por Savigny era que a coleta de galhos caídos no chão, à beira do Reno, era absolutamente necessária à sobrevivência dos camponeses alemães que os utilizavam na produção de fogo. Essa catação constituía costume consolidado (GUERRA FILHO, 1995).

Marx se negou a considerar a colheita de galhos caídos, praticada por camponeses, similar ao roubo de lenhas por meio do corte de árvores. Ele asseverava que uma lei não poderia alterar a natureza das coisas sob pena de tornar-se falsa (GUERRA FILHO, 1995). "Se a lei denomina furto de madeira uma ação que nem sequer

I Karl Marx foi aluno de Savigny no curso de Inverno da Universidade de Marburgo de 1836 a 1837; sob o tema 'Pandectas' estudavam as compilações do direito romano. 
constitui uma contravenção penal referente à madeira, está a lei, portanto, mentindo e o pobre é sacrificado por causa de uma mentira legal" (MARX,|96I, n.p.). Para Marx, recolher lenha caída e roubar madeira eram coisas essencialmente distintas, o que tornava impossível, portanto, equiparar um costume ao conceito de furto, sob pena de ferir o princípio da adequação (SOBREIRA FILHO, 20 I I ) "a natureza jurídica da coisa não pode, por isso, comportar-se conforme a lei, mas sim é a lei que deve comportar-se segundo a natureza jurídica das coisas" (MARX, I96।, n.p.).

Marx considerou também que, ao ignorar um costume sedimentado na região, qual seja, de recolher livremente os gravetos, Savigny contrariava a concepção defendida duramente pela Escola Histórica, para a qual o costume constituía fonte primária do direito (GUERRA FILHO, 1995). Marx reivindicou aos pobres o direito consuetudinário e afirmou que, "por sua natureza, pode ser apenas o direito dessas massas mais inferiores, desapossadas e elementares" (MARX, |96I, n.p.).

A criminalização da conduta consagrada pelo costume foi rejeitada por Marx, que se negou a admitir a sua compatibilidade como norma regulamentadora, pelo simples fato de ter sido emanada por um poder competente para produzi-la, e considerou que a produção de uma coalisão entre interesses impedia que a lei se harmonizasse com a ordem jurídica (SOBREIRA FILHO, 20 I I).

Por fim, Marx criticou a medida sancionadora que transpunha o campo do direito público para as relações jurídicas privadas, centrada na defesa de interesses privados, de natureza patrimonial, uma vez que a pena de trabalhos forçados seria aplicada à pessoa, e a multa prevista alternativamente não seria direcionada aos cofres públicos, mas ao particular ofendido em seu direito de propriedade - justiça patrimonial (GUERRA FILHO, 1995). Protestou, afirmando que "o proprietário da floresta não pode, por meio do Estado, adquirir o direito privado à punição pública" (MARX, | 96 I, n.p.). E atacou o uso da sanção penal que colocava os interesses privados e patrimoniais acima dos interesses sociais, além de denunciar o sacrifício desproporcional imposto aos desfavorecidos em relação às vantagens atribuídas aos donos de terras (SOBREIRA FILHO, 20I I). "Vencem os ídolos de madeira, caem as vítimas humanas!" (MARX, I96। , n. p.). "Le propriétaire a triomphé, l'intérêt s'est imposé au droit" (MICHEL, 1986, p. 18).

Sobreira Filho (20 I I) destaca que, no caso da lei sobre o furto de lenhas, foi a primeira vez que Marx emitiu uma manifestação de forma expressa e pontual sobre os problemas concretos e cotidianos, explicitados em questões econômicas.

Foi a partir da análise do caso acima descrito que Marx percebeu o problema da manipulação das leis por interesses alheios a seus legítimos propósitos, ou seja, a oposição existente entre a juridicidade aportada na consciência do povo e a legalidade dirigida pelos juristas na esfera social (CUSTÓDIO, 2013).

Nessa perspectiva, ele localizou uma contrariedade evidente entre a teoria e a prática fundamentada nos interesses de uma classe representada por Savigny e apontou para a "necessidade imperiosa de se realizar uma crítica da ideologia, que 
mostra contradições entre a prática de alguém e a sua própria concepção de mundo" (GUERRA FILHO, 201 I, p. 72).

\section{O FENÔMENO IDEOLÓGICO}

A utilização do termo ideologia nasceu durante a Revolução Francesa, quando uma corrente, liderada por Antoine Louis Claude Destutt, o conde De Tracy, autodenominada ideologista, sugeriu uma revolução institucional que propunha uma análise das ideias, uma ciência das ideias. Essa foi a corrente filosófica que dominou o ambiente intelectual francês entre os últimos anos do século XVIII e o início do século XIX. Os ideologistas defendiam que educar era reconstruir os caminhos que os homens produzem quando seguem a natureza, e que, sob a orientação de um filósofo, o conhecimento estaria ao alcance de todos (PIMENTA, 20 I 2).

As ideias do iluminista liberal objetivavam um avanço nas ciências como um progresso para a humanidade, que, por meio do livramento dos dogmas religiosos e políticos, seriam capazes de romper com o Antigo Regime. Esses conceitos foram reunidos na obra Les Eléments d'idéologie, publicada em 1803 (PEREIRA, 20 I 6).

No projeto científico de De Tracy, "a ideologia deveria servir como base para todos os ramos do conhecimento, especialmente para as ciências humanas" (ARAUJO COSTA, 200 I, p. 60). A filosofia era considerada como uma matéria propedêutica.

Com a queda de Robespierre, no golpe do Termidor, foi instituída, em Paris, a École Normale, academia destinada à formação de educadores para as províncias. Coube a De Tracy a organização de um curso de ciências morais e políticas, no qual ele introduziu a nova ciência baseada no estudo sistemático de ideias (ARAUJO COSTA, 200 I , p. 60). Porém, o conceito de que a filosofia pudesse ser a introdução a outro sistema perdeu força com a substituição da recém-criada escola pelo Instituto Nacional, cujo objetivo era produzir estudos de utilidade geral e que enaltecessem a glória da república (PIMENTA, 20I2).

Embora o termo ideologia tenha sido cunhado por De Tracy para sua proposta científica, foi Napoleão Bonaparte que alterou a acepção da palavra, atribuindo-lhe sentido pejorativo e popularizando sua definição (CARNIO, 2009).

Não obstante o fato de que os ideólogos fossem nobres, afinados com a revolução, as ambições centralizadoras e imperialistas de Napoleão não Ihes agradavam, da mesma forma que o discurso do grupo pela república contrariava o soberano. Para desclassificar as idéias propagadas, Napoleão ridicularizou os ideólogos, pejorando a doutrina como especulativa e desvirtuada da realidade do domínio político (TOMPSON, 20I I). Alcunhou-os de metafísicos (PEREIRA, 2016).

Após uma campanha desastrosa na Rússia, Napoleão retornou a Paris, acusando os ideólogos de subverter o Estado e o poder da lei. Em discurso, atribuiu os males da França à ideologia, ridicularizou suas pretensões e classificou a doutrina como especulativo-abstrata. Conforme a posição de Bonaparte enfraquecia, seus ataques à ideologia tornavam-se mais intensos (TOMPSON, 20 I I). 
Nessa perspectiva, a ideologia passou a representar uma forma de desautorização de discursos e renúncia aos debates. Cabe ressaltar que foi exatamente essa definição de ideologia, tecida como abstração utópica e artificial, que veio a ser congregada e difundida pela tradição clássica de Marx (FREITAS; FEITOSA, 20।4).

Durante o período em que ficou exilado na França (de 1844 a 1845), Marx se familiarizou com o trabalho dos ideólogos liderados por De Tracy e atacados por Napoleão. Seguindo o uso que Napoleão fez do termo ideologia, Marx e Engels compararam os ideologistas franceses com os seus compatriotas, ao afirmar que também estes trabalhavam sob a ilusão de que a batalha real a ser travada seria no campo das ideias, estimando exorbitantemente o papel e o valor das ideias na história e na vida social (TOMPSON, 20 I I).

Em A ideologia alemã, obra publicada em 1846, Marx e Engels ressaltam que "nenhum desses filósofos teve a ideia de se perguntar qual era a ligação entre a filosofia alemã e a realidade alemã, a ligação entre a sua crítica e o seu próprio meio natural" (MARX; ENGELS, 1989, p. 10) e, nesse sentido, não conseguiam dar força prática e efetiva à sua crítica (TOMPSON, 201 I).

Segundo os autores, os seguidores da Escola Histórica aspiravam a uma transformação somente com a força da crítica e do pensamento iluminado, sem dar importância ao papel da batalha prática como elemento de intervenção na realidade (PEREIRA, 20I6), e, para os historicistas, "o importante era o espírito e a luta para mudar a sociedade, era uma luta espiritual, uma luta crítica” (LÖWY, 2008, p. 23).

Marx e Engels defenderam que o método utilizado estava equivocado, uma vez que as mudanças não acontecem em decorrência de alterações no campo das ideias, mas na infraestrutura econômica de uma sociedade. Por essa razão, escreveram, em teses sobre Feuerbach, que "os filósofos até agora somente se limitaram a explicar o mundo de formas diferentes, mas o que é necessário é transformá-lo" (MARX, ENGELS, 1989, p. 103).

Para os críticos alemães, o problema dos ideologistas estava no fato de que, ao elaborarem teorias, relegavam para segundo plano a realidade material, invertendo a ordem de partir da realidade e chegar às ideias; ao contrário, partiam das ideias para a realidade e, nesse contexto, mesmo que sem intenção, projetavam as contradições do mundo real na consciência, criando soluções exclusivamente espirituais ou discursivas que ocultavam as adversidades existentes (MARX, ENGELS, 1989, p. 103).

Desde então, Marx já desenvolvia a ideia de que as transformações econômicas estão na raiz das alterações históricas, sociais, políticas, culturais e jurídicas (ANAV, 2017). Cabe destacar que, embora de forma embrionária, essa constatação foi antecipada por De Tracy, para quem "os interesses econômicos eram os determinantes finais da vida social" (DE TRACY apud EAGLETON, 1997. p. 69).

No livro de 1846, Marx e Engels se referem à ideologia como ilusão, falsa consciência, um sistema de crenças, e trazem o conceito de que o ideólogo é alguém que altera o sentido das relações entre a ideia e o real (CARNIO, 2009). Por conseguinte, 
definem ideologia como "uma doutrina teórica e uma atividade que olha erroneamente as ideias como autônomas e eficazes e que não consegue compreender as condições reais e as características da vida socioeconômica" (MARX, ENGELS apud TOMPSON, 201 I, p. 52).

Verifica-se que, a partir da análise da lei proposta por Savigny, Marx despertou para a sua crítica da ideologia, ao perceber as contradições entre as práticas e as concepções do mundo de alguém identificado com a sobreposição de interesses de uma classe sobre outra (CARNIO, 2009).

Nesse contexto, a maior contribuição de Marx foi a alteração da concepção atribuída à palavra ideologia. A partir da ideologia alemã, o termo perdeu o conceito de modo ingênuo de pensar o mundo para significar um modo proveniente das relações de classe e das condições econômicas, num sistema em que se ocultam as relações de dominação com objetivo de manter a posição estabelecida. Assim, passamos a entender a ideologia não somente como uma visão falsa do mundo, mas como uma visão falsa que é direcionada para que a classe dominante mantenha sua posição privilegiada na sociedade (ARAUJO COSTA, 200I).

A ideologia passou a ser definida como um sistema de representações que sustenta relações existentes de dominação de classe por meio de direcionamento de pessoas para o passado, em detrimento do futuro, ou para imagens e ideais que acobertam as relações de classe e desviam da busca coletiva de transformação social (TOMPSON, 201 I).

De tal modo, a ideologia é posta como um imaginário social em que a atenção da realidade é bloqueada ou oferece compensações ilusórias para as desgraças da vida e da sociedade. O imaginário reprodutor bloqueia o conhecimento, pois só reproduz a realidade, porém atribuindo-lhe aspectos sedutores, mágicos, cheios de sonhos, justificador de uma ilusão tal qual ela parece ser (CHAUI, 2000). Reconhece-se a ideologia como um valor que transcorre pelas pessoas, alienando sujeitos e anulando-os do seu protagonismo.

Penso, pois, a ideologia como auto-imagem da sociedade, imagem que é construída pela sociedade, a partir da religião, da filosofia, da ciência, da arte da educação, do direito, da indústria cultural, difundida e manipulada pelos grupos sociais que detém a hegemonia e o poder, e que dispõe dos instrumentos de manipulação, principalmente, da educação, do direito e dos meios de comunicação social.(COELHO, 1985, p. 67)

Numa perspectiva semelhante trabalhou Castells em $\bigcirc$ poder da comunicação. Para ele, o poder estava baseado no controle da informação e da comunicação num espaço em que as dominações atuam sobre a mente humana por meio de mensagens informativas. Ressaltou a necessidade de entender o pensamento humano para compreender o processamento dessas mensagens e a interferência que elas são 
capazes de produzir no plano político, local em que, deliberadamente, políticos intervêm nas redes de comunicação para promover seus interesses, influenciar decisões e garantir o acesso às posições de poder estatal (CASTELLS, 20 I 5).

Importante ressaltar que, nesse sentido, resta a dúvida sobre se seria possível a existência de um pensamento não ideológico, desvinculado, livre de pressupostos. Segundo o pensamento marxista, não. Mas isso não implica considerar todo pensamento moldado como ideológico, pois, nesse ponto, é preciso diferenciar ideologia de mero condicionamento social de pensar e desvendar a valoração dos pontos de vista socialmente determinados e em que medida influenciam na apreensão do real (EAGLETON, 1997).

Retomando o raciocínio de que ideias são dominadas por uma classe detentora do poder, Marx deslocou para o campo do pensamento as relações materiais dominantes:

Os pensamentos da classe dominante são também, em todas as épocas, os pensamentos dominantes; em outras palavras, a classe que é o poder material dominante numa determinada sociedade é também o poder espiritual dominante. A classe que dispõe dos meios de produção material dispõe também dos meios de produção intelectual, de tal modo que o pensamento daqueles aos quais são negados os meios de produção intelectual está submetido também à classe dominante. Os pensamentos dominantes nada mais são do que a expressão ideal das relações materiais dominantes... são as ideias de sua dominação. (MARX; ENGELS, 1989, p. 48)

Elabora-se, portanto, que "a ideologia é uma projeção contínua da infraestrutura sobre a superestrutura, no sentido marxista dessas palavras, que exprimem a influência da base econômica sobre as demais facetas da vida social" (SANTOS FILHO, 2004, p. 28). Nessa senda, a burguesia, reconhecida como classe dominante, preocupada em manter a ordem, usufrui da sua posição na estrutura social para limitar o processo de conhecimento da sociedade (PEREIRA, 20 I6).

Embora a ideologia vincule o discurso e as problemáticas do pensador, ela se constitui independentemente de motivações subjetivas. $\bigcirc$ fenômeno ideológico não se verifica por fatores individuais, como a má-fé e a capacidade intelectual do indivíduo. $\bigcirc$ fato é objetivo. Pode-se constatar a existência de cientistas capacitados que involuntariamente são acometidos por restrições cognitivas (PEREIRA, 2016). Isso não implica, no entanto, afirmar a inexistência de intelectuais que voluntariamente deformam o próprio discurso, desenvolvendo teorias que camuflem o movimento real, baseado em interesses extracientíficos. Aqueles que, embora influenciados por ilusões ideológicas, produziram com lealdade na busca da verdade, Marx chama de ideólogos clássicos. De outro modo, aqueles que, por razões cínicas, 
conscientemente, submetem o conhecimento a interesses políticos, cujo objetivo seja a criação de uma falsa ratificação de interesses preconcebidos, Karl nomeia de ideólogos vulgares (MARX, 1983).

Para que a ideologia possa exercer sua dominação, ela lança mão de artifícios que estabeleçam e mantenham as relações de autoridade. Em Ideologia e cultura moderna,Thompson (20I I ) apresenta cinco modus operandi de como a ideologia atua para exercer sua dominação, mas esclarece que as formas exibidas não são taxativas ou exaustivas e podem, ainda, agir de forma individual ou de maneira associada.

A primeira forma é a legitimação, em que as relações de dominação podem ser estabelecidas e sustentadas por serem representadas como legítimas, ou seja, justas e dignas de apoio. A segunda se dá pela dissimulação. Nesse contexto, dominações são ocultadas, negadas, obscurecidas ou representadas de forma que a atenção seja desviada. A terceira forma de operar a ideologia se apresenta com a unificação, ou seja, a dominação se dá com a construção de uma identidade coletiva que liga os indivíduos independentemente das diferenças que os separam. A quarta maneira de atuação da ideologia é a fragmentação. Nesse método, segmentam-se os indivíduos que, unidos, poderiam ser um desafio real em grupos rivais, direcionando as forças de um grupo contra o outro, taxado como perigoso e ameaçador. $\bigcirc$ último modo de atuação da ideologia, segundo Tompson, é a reificação. Por esse método, os caracteres sóciohistóricos dos fenômenos são ofuscados ou eliminados e passamos a acreditar nos acontecimentos como naturais, eternos ou passivizados (TOMPSON, 201 I).

Em Topologia da violência, Han (2017a) verifica a existência da violência desde as sociedades arcaicas, em que a força bruta mortal fazia as vezes de uma insígnia de poder. $\bigcirc$ autor relata que esse cenário permanece na Antiguidade, tempo em que a encenação da violência fazia parte da sociedade, e continua na era Prémoderna, com o teatro da crueldade, que, além de exercer, passa a focalizar e expor a violência. Naquelas sociedades, a violência não se escondia. $\bigcirc$ autor chama a atenção, porém, para o fato de que modernamente a violência da força bruta vem perdendo legitimidade e, nesse contexto, suas formas de manifestação se modificam. A encenação ostentatória se camufla, e a violência se desloca para espaços invisíveis. Nas sociedades modernas, a violenciaé viral, microfísica, neural, subcomunicativa, virtual, psíquica; a brutalidade se desloca do externo para o interno, do físico para o psíquico. "Há coisas que nunca desaparecem; dentre elas está a violência" (HAN, 2017a, p. 7).

Essa mesma alteração paradigmática observada por Han no que se refereà violência pode ser projetada para as dominações, espaços em que o fenômeno ideológico provocou transformações. As dominações, antes impostas à força, agora instrumentalizadas pela ideologia, sofisticaram-se, internalizaram-se, tornaram-se psíquicas, operam pelo consenso.

Essa característica foi antecipada por Habermas (1968, p. 47) ao perceber que, nas sociedades capitalistas avançadas, a dominação tendia a perder o seu caráter 
explorador e dominador para tornar-se racional, sem que se desvanecesse a dominação política. $\bigcirc$ autor observa que, embora essa repressão permanecesse, ela tendia a desaparecer do consciente coletivo por ter assumido um novo caráter de legitimação, instrumentalizado pela crescente produtividade que proporciona comodidades à sociedade que se reconhece satisfeita.

\section{IDEOLOGIA JURÍDICA}

A manipulação da ideologia é elaborada no sentido de manter uma ordem social vigente, com a ocultação da realidade e a substituição de valores, ideais e mitos que passam a ser absorvidos pela coletividade como verdadeiros e adequados (COE$\mathrm{LHO}$, 1985).

Se o direito é um sistema de regras coercitivas que regem as relações sociais e as normas legisladas por um sistema político, parece óbvio que tenha conexão com o fenômeno ideológico (SYPNOWICH, 20|4). Assim, o direito pode ser entendido como uma projeção normativa que instrumentaliza princípios ideológicos, como a segurança e a certeza, e as formas de controle de determinado grupo social (WOLKMER, 2003).

A manifestação do fenômeno ideológicoé verificada, segundo Coelho, no próprio conceito de direito, ao descrever que, apesar de a conceituação tradicional exibir-se esculpida na ideia de bem, do equilíbrio, da justiça, da paz e do amor, a humanidade, desde sempre, se serve do direito para semear injustiças, ódio, vingança, tortura, miséria, egoísmo, corrupção, intolerância, tirania e opressão. Exemplos não faltam. Tudo em nome da justiça (COELHO, 1985).

Correas (1995) direciona suas críticas ao Estado, ao afirmar que este nunca produziu normas cujo objetivo tenha sido a melhora do nível de vida dos setores empobrecidos e desprotegidos. Para ele, todas as formas de conduzir a ideia de que o Estado produz normas para beneficiar os setores desprivilegiados é uma apologia do poder que atua em proveito da pobreza.

Na sociedade atual, as relações não se apresentam como são, os indivíduos se confundem, e os papéis sociais se misturam. Vive-se em uma sociedade cansada, local em que sujeitos de desempenho renunciam ao pensar, estão muito abatidos para discussões. A violência de hoje nos toca muito mais a partir do conformismo do consenso do que do antagonismo do dissenso.(HAN, 20 I7b) E é justamente nesse ambiente social que a ideologia encontra terreno fértil para exercer sua dominação.

Nessa senda, "Toda a atividade jurídica é uma prática ideológica"(WOLKMER, 2003, p. 154), e, dentre as formas difundidas do processo ideológico no campo jurídico, destaca-se a ideologia da igualdade jurídica.

No núcleo dessa forma ideológica, reside a existência aparente de um mundo livre, justo e de iguais, que se materializa pela compreensão da existência de uma igualdade concernente ao status jurídico das pessoas, com ausência de diferenças qualitativas entre os cidadãos perante o Estado. Nessa lógica, o direito se apresenta 
como instrumento essencial para a sustentação de uma ideologia que distorce a realidade (PEREIRA, 2016).

direito desenvolve o papel de falso universalizador à medida que propaga princípios que constroem e reforçam a imagem de uma comunidade de iguais ficta: "Legal discours eshave the legitimating power, they do because they sketch pictures of widely shared, wistful, inchoate visions of anideal-asociety of dealings between genuinely freeand independente quals" (GORDON, 1987, p. 16).

Nas sociedades em que se vive em sistemas de igualdade, o discurso da exploração compadece como contrassenso e é nesse ponto que o direito se apresenta como coluna basilar para o funcionamento do capitalismo: "a igualdade formal verificada no âmbito estatal-jurídico cumpre a função ideológica de inviabilizar as relações capitalistas de exploração ao representar como equitativas relações de desigualdade" (PEREIRA, 2016, p. 317 ).

No direito privado, a noção civilista da autonomia da vontade, pressuposto dos contratos sinalagmáticos e fundamento da teoria das obrigações, é um excelente exemplo de manipulação ideológica. Independentemente da sociedade que se observe, a vontade individual não é livre. A influência aparece no consumismo, nas cláusulas de adesão, nas demandas do mercado que ditam a oferta e a procura, no medo da violência, na luta pela sobrevivência: "quem tem fome não é livre" (COELHO, 1985, p. 70).

A verificação da liberdade decisória se torna impossível quando a igualdade entre as partes não transpassa o limite da formalidade. Todavia, a noção de isonomia sedimentada ideologicamente impede um discurso de protesto. Entre os indivíduos de uma sociedade que se reconhecem iguais, a lógica da exploração não prevalece.

$\mathrm{Na}$ hermenêutica jurídica, o influxo ideológico também opera de forma incontestável. A valoração da ideologia permite tanto criar falsas situações de antinomia quanto instrumentalizar o intérprete para encontrar soluções exegéticas, persuadindo a dialética na busca da decisão favorável. Observada a antinomia ou a lacuna, o operador do direito trabalha para apresentar fatores extrapositivos como positiváveis, manipulando discursos persuasivos e partidários na busca do melhor resultado para si (DINIZ, I98I, p. 246).

"Toda estrutura jurídica reproduz o jogo de forças sociais e políticas, bem como os valores morais e culturais de uma dada organização social" (WOLKMER, 2003, p. 155). Observa-se que os discursos legislativos estão impregnados com insígnias e imagens que, na maior parte das vezes, racionalizam e justificam infinitas configurações de ordem social apresentadas como naturais, necessárias e justas (GORDON, 1987).

Nos trabalhos de Marx, foram apresentadas as bases para a análise da sociedade capitalista, coletividade na qual o fundo teórico é a lei do valor. Considerando que o direito moderno é capitalista, a sua função maior está na proteção da produção e circulação de bens: "os motivos são os números: são uma incitação para suprir as 
razões do Direito, e quem duvidaria que o interesse privado possui muitas incitações para supri-las?"(MARX, |96।, n.p.).

Embora as constatações e análises sobre a influência ideológica na sociedade tenham sido propostas por Marx, ironicamente, o alemão acabou por ser criticado pela ideologia dogmática e pela relativização moral de sua doutrina. Em A sociedade aberta e seus inimigos, Popper ( 1974 ) acusa Marx de abandonar sua origem de moral humanitária em troca de uma ideologia que não admite contradições; condena suas ideias como reacionárias, comparando-as às ideologias totalitárias; censura a ilusão do socialismo científico, apelidando-o de superstição primitiva; combate a parcialidade de suas análises por se basearem no capitalismo limitado territorialmente; e reconhece a ditadura do proletariado, apesar de Marx ter demonstrado um apego fundamental à liberdade. Por fim, acresce ser "um perigo insistir demasiadamente no economismo e interpretá-lo como doutrina de que todo desenvolvimento social depende de condições econômicas" (POPPER, I974, vol. II, p. | | 5).

Sob essa perspectiva, admite-se que nem Marx foi capaz de trabalhar desvinculado de influência ideológica em sua doutrina, mas ressalta-se que tais constatações não desmerecem os trabalhos desenvolvidos no sentido de constatar e direcionar estudos acerca da manipulação de ideias na sociedade.

O pensamento de Marx flui no sentido de afirmar que, apesar de o direito moderno ser capitalista, uma cortina ideológica insiste em desvincular política de economia. Essa ruptura distancia o aparato econômico do jurídico-estatal e passa a ideia equivocada de que cada tema segue uma lógica própria. Desse modo, os indivíduos são levados pela errônea ideia de que, no espaço político, as pessoas se relacionam desvinculadas das questões econômicas, na qualidade de cidadãos inseridos em relações em que as presunções de exploração são apagadas, supridas e trocadas (PEREIRA, 20 |6).

Adverte-se que o aspecto econômico permanece como instância imprescindível na luta por um outro mundo e que, embora idealizações das classes dominantes tentem desassociar instâncias econômicas da vida humana, no fundo, são interdependentes. Essa desagregação da visão geral distorce a ideia de que a teoria econômica não deve se deter em valores humanísticos e impossibilita o progresso da humanidade. Previnese que, após essa dissociação, o mercado se transforma em valor elevado e onipotente, e a sociedade é direcionada, ideologicamente, a acreditar que valores inferiores devem ser sacrificados para evitar deformidades (HINKELAMNERT, 20 I 4).

Ao separar função jurídica de aparato econômico, cria-se a falsa ideia de que cada um segue uma dialética própria. Separados, as questões econômicas ganham maior destaque e submergem as demais reivindicações que, sem possibilidade de proeminência, continuam relegadas e analisadas de forma secundária. Numa sociedade em que prevalece a lógica da eficiência econômica, nenhuma outra hipótese encontra coerência: "O indispensável torna-se inútil por não conseguir ser considerado no cálculo da utilidade" (HINKELAMNERT, 2014, p. 199). 
Esse é o posicionamento sustentado por Hayek e outros membros da Escola Austríaca, que defendem a inexistência de alternativas para além da lógica de resultado de mercado. Sob essa ótica, consideram a justiça social, como defendida pelo capitalismo de Estado, uma ilusão por ponderarem que a justiça distributiva só funciona em pequenos grupos. Além disso, na visão hayekiana, justiça é uma palavra que só se aplica a ações, nunca a resultados. Qualificam o capitalismo de Estado como opressor e totalitário, em que o planejamento é reconhecido como antidemocrático no sentido de que a burocracia impede tomadas de decisões imediatas. Atacam a democracia representativa, ao afirmar que, nesse sistema, somente "os piores chegam ao poder", pois apenas inescrupulosos populistas são capazes de prometer ao povo que o Estado vai resolver seus problemas. Hayek chama a atenção para o fato de que o direito não encampa a função precípua de melhorar o mundo, mas de garantir as regras de bem viver e instrumentalizar a economia, ${ }^{2}$ pois as realizações dependem do progresso econômico (HAYEK, 1990). Trata-se do uso de um juízo racional.

Inspirado em Max Weber, Habermas (1968) define racionalidade como atividade econômica capitalista guiada pelo direito privado burguês em que as esferas públicas ficam submetidas a critérios de decisão racional, espaço em que as escolhas das alternativas, em ações lógicas, são direcionadas a um fim específico, qual seja, a eficiência econômica. Entretanto, cita Freud, ao destacar que o método racional opera para que o verdadeiro motivo, isto é, a manutenção da dominação, permaneça oculto.

Em Hinkelammert, os axiomas de Hayek são considerados utópicos. Em Crítica da razão utópica, foram edificadas análises ao neoliberalismo que colocam o mercado como ponto central, sem considerar que o seu conceito ideal se materializa num progresso infinito e, dessa forma, inalcançável. Acastela-se que os defensores do mercado partem de uma realidade precária (trabalham com hipóteses de mercados perfeitos e em equilíbrio) e polarizada (desconsideram a satisfação das necessidades humanas por considerá-las irrelevantes da realidade) num contexto em que só os criteriosmercantis são analisados (HINKELAMMERT, 1986). Nesse espaço, trabaIham sob uma influência ideológica que impossibilita o desenvolvimento de ações independentes de condicionamentos político-ideológicos. São os números incitando a produção jurídica: "o interesse não pensa: calcula". ${ }^{3}$

A partir do pressuposto de que as limitações humanas, conscientes, ou não, impedem a apreensão da realidade, a proposta que se apresenta consiste no desenvolvimento de um modelo possível e desejável, com inclusão do ético na racionalidade instrumental que valorize o humano, para impedir que fins sejam alcançados a qual-

2 Para Hayek, o controle da economia gera indivíduos escravos e dependentes de planejamento.

3 Frase escrita por Marx e publicada na Gazeta Renana, n. 305, em $1^{\circ}$ de novembro de 1842. Documento compilado em MARX, |96I, n.p. 
quer preço. A ética mercantil disseminada provoca distorções na vida humana, de modo que as necessidades superam o simples consumir. Assegurar o que é essencial hoje implica garantir possibilidades futuras (HINKELAMMERT, 1986).

\section{CONSIDERAÇÕES FINAIS}

A partir do estudo apresentado, conclui-se pela impossibilidade de comportamentos sociais desvinculados de condicionamentos ideológicos. Nesse campo, o direito, cuja produção se restringe a uma minoria detentora de poder, com suas múltiplas possibilidades de manipulação por métodos coercitivos ou persuasivos, também pode sofrer a projeção de uma realidade distorcida e trabalhar, mesmo que inconscientemente, na legitimação de circunstâncias mercadológicas em que a epistemologia jurídica é transformada em detrimento do valor-fonte sobre o qual repousa o escopo do direito.

Os condicionamentos ideológicos sempre influenciaram e continuarão a determinar as decisões sociais; no entanto, a atenção deve ser direcionada no sentido de não permitir que os destinatários finais, razão pela qual e para quem o direito foi criado, sejam inseridos numa disputa em que os meios se sobrepõem aos fins, e o desígniojurídico fundamental, o ser humano e suas necessidades essenciais sejam relegados a instâncias subalternas.

\section{REFERÊNCIAS}

ANAV, Roberto Vital. O retorno de Karl Marx: a redescoberta de Marx no século XXI. São Paulo: Serpente. Fundação Perseu Abramo, 2017.

ARAUJO COSTA, Alexandre. Introdução ao direito:uma perspectiva zetética das ciências jurídicas. Porto Alegre: S. A. Fabris, $200 \mathrm{l}$.

ASHTON, Peter Walter. A história da elaboração do BGB Alemão. Revista da Faculdade de Direito da UFRGS, Porto Alegre, n.31, p. 223-228, 2013.

BILLIER, Jean Cassien; MARYIOLI, Aglaé. História da filosofia do Direito. Barueri, SP: Manole, 2005.

BOBBIO, Norberto. O positivismo jurídico: lições de filosofia do direito. Tradução e notasMárcio Pugliesi. São Paulo: Ícone, 1995.

BROOKS, Clem; MANZA, Jeff; COHEN, Emma D., Political ideology and immigrant. Socius: sociological research for a dynamic world acceptance, Sept. 2016 Disponívelem: <http://journals.sagepub.com/doi/ full/I 0.1 | 77/2378023 | | 666888 | \# articleCitationDownloadContainer>. Acesso em: 15 mar. 2018. 
CARNIO, Henrique Garnellini. Direito e ideologia: o direito como fenômeno ideológico. Panóptica, v. 4, n. 3, 2009. Disponível em:<http://www.panoptica.org/ seer/index.php/op/article/view/Op_4.3_2009_95-107>. Acesso em: 2 mar. 2018.

CASTELLS, Manuel. O poder da comunicação. Rio de Janeiro: Paz e Terra, 20। 5.

CHAUI. Marilena. A ideologia da Competência. Escritos de Marilena Chaui, volume 3. Organizador André Rocha, I ${ }^{a}$ ed.; I. Reimp. Belo Horizonte: Autentica Editora; São Paulo: Editora Fundação Perseu Abramo, 2016.

CHAUI. Marilena. Convite à filosofia. São Paulo: Editora Ática, 2000.

CHAUI. Marilena. O que é ideologia. São Paulo: Brasiliense, 1981.

COELHO, Luiz Fernando. Ideologia e Direito. Sequência:Estudos Jurídicos e Políticos,Florianópolis, v. 6, n. II, p. 67-75. Jan. 1985.

CORREAS, Oscar. Crítica da ideologia jurídica: ensaio sócio-semiológico. Tradução: Bruno Bueno. Porto Alegre: S. A. Fabris Editor, 1995.

COSTA, Alexandre Araújo. Direito e método: diálogos entre a hermenêuticafilosófica e a hermenêuticajurídica. 2008. 42 I f. Tese (Doutorado em Direito) - Faculdade de Direito, Universidade de Brasília, Brasília, 2008.

CUSTÓDIO, Matheus Zmijevski. $\bigcirc$ historicismo jurídico do pensamento montesquiano em Friedrich Carl Von Savigny e suas consequentes implicações no materialismo histórico marxista. Cadernos do Programa de pós-graduação em Direito UFRGS, Porto Alegre, v. 8, n. I, p. I-21, 2013.

DINIZ, Maria Helena. As lacunas do direito. São Paulo: Revista dos Tribunais. I98I.

EAGLETON, Terry. Ideologia: uma introdução. São Paulo: Editora Unesp/Boitempo, 1997.

ENDERLE, Rubens. O jovem Marx e o "Manifesto filosófico da escola histórica do direito”. Crítica Marxista, São Paulo, v. 20, p. I | | - | 22, 2005.

FERRAZ JUNIOR, Tercio Sampaio. Teoria da norma jurídica. 3. ed. Rio de Janeiro: Forense, 1999.

FREITAS, Lorena; FEITOSA, Enoque. Ideologia e direito a partir do quadro teórico de Karl Mannheim. In: CASTRO, Matheus Felipe de; AMAVA, Lídia Patrícia Castillo. (Org.). Teoria crítica do Direito. I. ed. Florianópolis: Conpedi, 20 I 4, v. I , p. 54-7I.

GONZAGA, Álvaro Luiz Travassos de Azevedo, direito natural e jus naturalismo. 
Tomo de teoria geral e filosofia do direito. Enciclopédia jurídica da PUC-SP. Editado pela Pontifícia Universidade Católica de São Paulo, São Paulo, abril de 2017. Disponível em: <http://www.academia.edu/33264058/DIREITO_NATURAL_E_ JUSNATURALISMO_-_ENCICLOPÉDIA JURIIDICA_DA_PUC-SP_-_por_Álvaro_ Gonzaga >. Acessoem: 10 mar. 2018.

GORDON, Robert W. Law and ideology, Turkkun, v. 3, n. I, p. 14-18, 8387, April 1987. Disponível em: <http://www.tikkun.org/nextgen/wp-content/ uploads/20 I I/I2/Law-and-Ideology.pdf>. Acesso em: 19 mar. 2018.

GUERRA FILHO, Willis Santiago. A contribuição de Karl Marx para o desenvolvimento da ciência do direito. Revista da Faculdade de Direito. Curitiba, a. 28, n. 28, p. 6974, 1994/95.

HABERMAS. Técnica e ciência como ideologia. Lisboa: Editora Setenta, 1968.

HAN, Byung-Chul. Topologia da violência. Petrópolis, RJ: Vozes, 2017 a.

HAN, Byung-Chul. Sociedade do cansaço. Petrópolis, RJ: Vozes, 2017b.

HAYEK, Friedrich August von. O caminho da servidão. 5. ed. Rio de Janeiro: Instituto Liberal, 1990.

HINKELAMMERT, Franz. Crítica à razão utópica. São Paulo: Edições Paulinas, 1986.

HINKELAMMERT, Franz. Mercado versus direitos humanos. Coleção Novos caminhos da teologia. São Paulo: Paulus, 2014.

JOUANJAN, Oliver. De la vocation de notre temps pour la sciencie du droit. Revue européenne des sciences sociales. European Journal of social Sciences. XLI 128/2003. La preuve en Sciences sociales, p. 129-144.

KLINE, Donna C. Dominion and wealth: A critical analysis of Karl Marx Theory of Commercial Law.Sovietica v. 49. Dordrecht, Holand: ReidelPublishingCompany, 1987.

LÖWY, Michel. As aventuras de Karl Marx contra o Barão de Münchhausen: marxismo e positivismo na sociologia do conhecimento. 9. ed. São Paulo: Cortez, 2008.

MARCUSE, Herbert. Industrialização e capitalismo na obra de Max Weber. In: Cultura e sociedade. São Paulo: Paz e Terra, v. 2, 1998.

MARX, Karl. Manifesto da Escola Histórica do Direito: crítica ao jusnaturalismo e ao positivismo no domínio do direito. Tradução Emil Asturig von München. 2006. 
Disponívelem: <http://www.scientific-socialism.de/KMFEDireitoCAP5Port.htm >. Acesso em 15 mar. 2018.

MARX, Karl. Debates acerca da lei sobre o furto de madeira por um Renano. Gazeta Renana. 1842 In: Obras de Marx e Engels, vol. I, Berlin: Dietz, p. 109-147, 196 I. Concepção e organização, compilação e tradução Emil Asturing von München. Disponívelem: <http://www.scientific-socialism.de/KMFEDireitoCAP22Port.htm>. Acesso em: II mar. 2018.

MARX, Karl. O capital: crítica da economia política. Volume I: $\bigcirc$ processo de produção do capital. Trad. Regis Barbosa e Flávio R. Kothe. São Paulo: Abril Cultural, 1983.

MARX, Karl; ENGELS, Friedrich. Ideologia alemã. Tradução: Luis Cláudio de Castro Costa. São Paulo: Martins Fontes, 1989.

MICHEL, Jaques. Marx et la loi sur les vols de bois. Les leçon du droit coutumier. Le coutume e la loi. Textes réunis par C. Journès, PUL, 1986.

PEREIRA, Mozart Silvano. O sentido do conceito de ideologia em Marx e a questão da igualdade jurídica.Revista Insurgência, Brasília, ano 2, v. 2, n. I , p. 295-32 I , 20 I 6.

PIMENTA, Pedro Paulo. Resenha: DESTUTT de TRACY. Oeuvres completes. Ed. Clause Jolly. Volume I: Premiers écrits: sur l'education publique. Paris: Vrin, 20 I I; Volume III: Élements d'idéologie, I. L'idéologie proprement dite. Paris: Vrin, 2012. Os Antípodas Franceses de Kant, Cadernos de Filosofia Alemã, n. 19, p. |6| - 174.

POPPER, Karl. A sociedade aberta e seus inimigos. 2 volumes. Belo Horizonte: Ed. Itatiaia; São Paulo, Ed. da Universidade de São Paulo, 1974.

ROMAR, Carla Teresa Martins. $\bigcirc$ acesso de imigrantes deslocados a força e de refugiados ao mercado de trabalho: perspectivas internacional e nacional. In: PINTO, Eduardo Vera-cruz et al. (Coord.). Refugiados, imigrantes e igualdade dos povos: estudo em homenagem a Antônio Gutierrez. São Paulo: Quartier Latin, 20 17, p. 357-367.

SANTOS FILHO, Gildo Magalhães dos. Ciência e ideologia: conflitos e alianças em torno da ideia do progresso. 2004. 25I f. Tese (Livre-docência em História das Ciências, das Técnicas e do Trabalho) - Faculdade de Filosofia da Universidade de São Paulo, São Paulo, 2004.

SOBREIRA FILHO, Enoque Feitosa. Direito e humanismo em Marx (a superação das esferas parciais de sociabilidade a partir de uma crítica inicial a forma jurídica contida nos textos da juventude). Revista Jur. Direito e realidade, Monte Carmelo, MG, v. I, n. I, p. 61-68, jan./jun. 201।. 
SYPNOWICH, Christine. Law and ideology. The Stanford Encyclopedia of Philosophy. Winter 2014 Edition, Ed. Edward N. Zalta. Disponível em: <https:// plato.stanford.edu/archives/win20 /4/entries/law-ideology/>. Acesso em: 16 mar. 2018.

TOMPSON, Jhon B. Ideologia e cultura moderna: Teoria social crítica na era dos meios de comunicação em massa. 9. ed. Petropolis: RJ, Vozes, 20I I.

WIEAKER, Franz. História do direito privado moderno. Lisboa: Calouste Gulbenkian, 1967.

WOLKMER, Antonio Carlos. Ideologia, estado e direito. 4. ed. São Paulo: Editora Revista dos Tribunais, 2003.

Recebido em: 14/06/2019 Aprovado em: 03/09/2019 